\title{
Hospital Acquired Infections in Low and Middle Income Countries: Root Cause Analysis and the Development of Infection Control Practices in Bangladesh
}

\author{
S. M. Shahida ${ }^{*}$, Anisul Islam², Bimalangshu R. Dey³, Ferdousi Islam¹, Kartik Venkatesh ${ }^{4}$, \\ Annekathryn Goodman4 \\ ${ }^{1}$ Department of Obstetrics and Gynecology, Dhaka Medical College Hospital, Dhaka, Bangladesh \\ ${ }^{2}$ Department of Anesthesiology, Border Guard Hospital, Dhaka, Bangladesh \\ ${ }^{3}$ Department of Medicine, Division of Hematology Oncology, Massachusetts General Hospital, Boston, MA, USA \\ ${ }^{4}$ Department of Obstetrics and Gynecology, Massachusetts General Hospital, Boston, MA, USA \\ Email: "sm.shahida@yahoo.com
}

Received 21 December 2015; accepted 18 January 2016; published 21 January 2016

Copyright (C) 2016 by authors and Scientific Research Publishing Inc.

This work is licensed under the Creative Commons Attribution International License (CC BY). http://creativecommons.org/licenses/by/4.0/

(c) (7) Open Access

\begin{abstract}
Nosocomial or hospital acquired infections are a major challenge for low and middle income countries (LMICs) which have limited healthcare resources. Risk factors include the lack of appropriate hospital facilities such as isolation units, bed space, and sinks; inadequate waste management, contaminated equipment, inappropriate use of antibiotics and transmission of infection from the hands of healthcare workers and family caretakers due to inadequate hand washing. Nosocomial infections increase the costs of healthcare due to added antimicrobial treatment and prolonged hospitalization. Since the prevalence of nosocomial infections is generally higher in developing countries with limited resources, the socio-economic burden is even more severe in these countries. This review summarizes the current knowledge on the risks of hospital acquired infections and summarizes current recommendations for the development of hospital infrastructure and the institution of protocols to reduce these infections in LMICs such as Bangladesh.
\end{abstract}

\section{Keywords}

Hospital Acquired Infections, Nosocomial Infections, Low and Middle Income Countries, Hand Washing, Waste Disposal

\footnotetext{
${ }^{*}$ Corresponding author.
}

How to cite this paper: Shahida, S.M., Islam, A., Dey, B.R., Islam, F., Venkatesh, K. and Goodman, A. (2016) Hospital Acquired Infections in Low and Middle Income Countries: Root Cause Analysis and the Development of Infection Control Practices in Bangladesh. Open Journal of Obstetrics and Gynecology, 6, 28-39. http://dx.doi.org/10.4236/ojog.2016.61004 


\section{Introduction}

Nosocomial or hospital acquired infections (HAIs) are a major challenge for low and middle income countries (LMICs) which have limited healthcare resources. HAIs are acquired infections that were not previously present in the patient prior to hospital admission [1]. The risk of health-care-associated infection has been estimated to be two to twenty times higher in developing countries than that of resource-rich countries with the percentage of infected patients exceeding 25\% [2]-[6]. The highest frequencies of nosocomial infections reported from hospitals in the Eastern Mediterranean and South East Asia Regions are 11.8\% and 10.0\% respectively. Accurate data on HAIs are not available due to limited record keeping and follow-up of patients in large urban hospitals in LMICs. Hospital acquired infection rates in Bangladesh may exceed 30\% in some hospitals [7].

Since HAIs are transmitted via hands of healthcare workers, hand washing remains the single most important means to prevent infection [8]-[10]. World Health Organization (WHO) publications have emphasized hand hygiene as a key measure to reduce nosocomial infections [7]. In 2006, the Ministry of Health and Family Welfare of Bangladesh signed an agreement with WHO for implementing the pilot activities on hand hygiene in Bangladesh and began a hand hygiene campaign, called as "Clean Care is Safer Care"-A Country Commitment [11].

In Bangladesh, health-care facilities have deficiencies in their structural design, which include the lack of sufficient sinks, bedside hand-rub dispensers and patient isolation facilities. Management of hospital waste is another neglected area [12]. The indiscriminant use of antibiotics also contributes to very high infections in developing countries [13]. Other factors such as the lack of awareness of infection control problems, and individual behavior can impede the prevention of hospital-acquired infections.

Nosocomial infections increase the costs of healthcare due to added antimicrobial treatment and prolonged hospitalization. Since the prevalence of nosocomial infections is generally higher in developing countries with limited resources, the socio-economic burden is even more severe in these countries [14]. This review summarizes the current knowledge on the risks of HAI and summarizes current recommendations for the development of hospital infrastructure and the institution of protocols to reduce HAIs in LMICs such as Bangladesh.

\subsection{Review of Existing Literature on Hospital Acquired Infections in Bangladesh}

Data on infection rates are limited to a small number of reports and can be divided into postoperative infections and hospital transmitted nonsurgical infections. A range of surgical infection rates has been reported in Bangladesh and is related to the type of surgery and the type of hospital where the surgery was performed. In an early report of sterilization procedures in Bangladesh, the death rate from infection was 21 per 100,000 procedures [4]. A review of 124 eclamptic patients who were delivered by cesarean section identified a morbidity rate including infections of 53\% [15]. There was a 7\% infection or sepsis rate after percutaneous nephrolithotomy [16]. Total thyroidectomy at the major teaching hospital of Dhaka had a postoperative wound infection rate of $2 \%$ [17]. In a review over 17 years at a mission hospital, there was a 3\% infection rate after pediatric surgical procedures for congenital anomalies [18]. These surgeries cannot be compared to surgeries done in public hospitals as these specialty procedures were performed by foreign visiting doctors who brought in their own equipment and sterilization techniques and thus did not have the same infrastructure challenges that local surgeons had. Reduction in surgical site infections is associated with minimally invasive surgeries. A review of laparoscopically assisted vaginal hysterectomy and vaginal hysterectomies at a tertiary diabetes hospital in Bangladesh showed an average febrile morbidity of $1.6 \%$ and urinary tract infections of $1.2 \%$, which is considerably lower than that for laparotomy cases [19].

A preliminary report from Dhaka Medical College Hospital (DMCH) in 1990 on antibiotic use for surgical site infection noted a reduction of HAIs form $3.9 \%$ to $0.5 \%$ with the initiation of antibiotics at induction of anesthesia [20]. This led to a department-wide change in antibiotic protocols for surgical procedures. However, nosocomial infections continue to be a major problem in big public hospitals. In 1991, a cross-sectional study on the nosocomial infection rate was 30\% at DMCH [21]. Twenty years later, a 2011 report from DMCH that reviewed infection rates on the surgical and burn units identified a $46.2 \%$ rate of nosocomial infections [22]. Wound infections were the most common type of infection followed by upper respiratory tract infection, urinary tract infection, and gastrointestinal infections. Risk factors included older age (62.5\% of infections), postoperative patients (63.5\% of infections), and an increasing number of visitors per patients per day [22]. An observational study at three public tertiary care hospitals in Bangladesh identified family caretakers as a potential source of infection transmission [23]. Family caregivers traditionally provide nursing care, cleaning care, support, and 
food to inpatients in Bangladesh [24]. During the observations of 2065 episodes of care, family members were observed washing their hands on only four occasions [23].

Non-surgical HAIs have also been studied in Bangladesh hospitals. The leading non-surgical HAIs include respiratory and gastrointestinal illnesses. The incidence of hospital-acquired diarrhea at three tertiary care public hospitals was 4.8 cases per 1000 patient days during the 2007-2010 period [25]. Transmission was through fecal-oral route. Risk factors included hospital stay greater than 3 days. Pediatric patients were much more susceptible to these HAIs than adult patients and three deaths from HAI diarrheal illness were reported in this study. The investigators identified a $4 \%$ incidence of diarrheal disease among healthcare workers who worked a mean of 2.5 days while ill suggesting another possible source of transmission to patients. Hospital-acquired respiratory illness in Bangladeshi tertiary care hospitals was evaluated in another study [26]. One out of every 20 patients with a hospital stay greater than 3 days developed a hospital acquired respiratory infection with an incidence rate of 6.1 cases per 1000 patient days. There was a $27 \%$ incidence of respiratory illness in health care workers working during this surveillance period again raising concern about healthcare worker-to-patient transmission of illness.

\subsection{Specific Examples of Barriers to Infection Control at a Large City Hospital in Bangladesh}

The physical hospital plant, the configuration of the patient wards, and caretakers of patients, both family members and healthcare workers, are major factors in hospital-acquired infections. Overcrowding in large tertiary care public hospitals is a major factor to the transmission of infections in LMICs [27]. The number of patients admitted often exceeds the number of beds available. This leads to doubling patients in each bed, and placing patients on the floor in hallways and stairwells (Figures 1-3). Patients with severe illness and contagious infectious diseases are housed in the same ward [26].

Infrastructure and contamination of the physical environment in three Bangladeshi hospitals identified many key concerns [28]. The physical structure was commonly an open ward with windows that could not be opened (Figure 4). Sanitation facilities were limited. The wards were overcrowded. Waste disposal was limited and included open buckets under patient beds that were emptied once a day. Surfaces such as floors, walls, bedcovers,

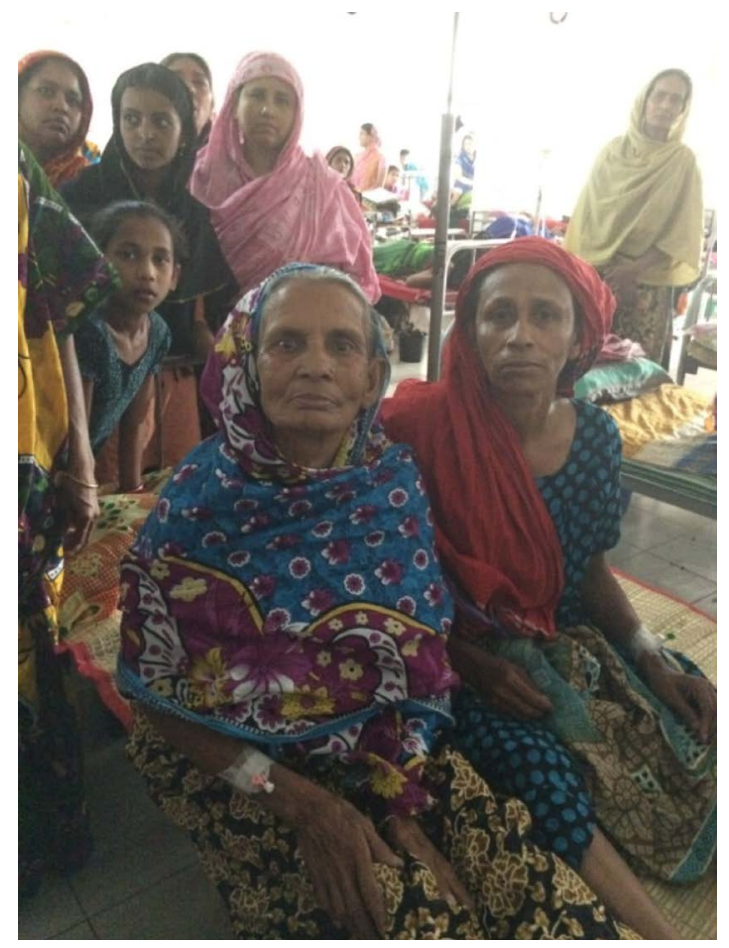

Figure 1. Women's gynecological ward, Dhaka medical hospital. Two patients to one bed and their family members who are staying with them (standing behind them in photo) (photograph taken with permission of patients and families). 


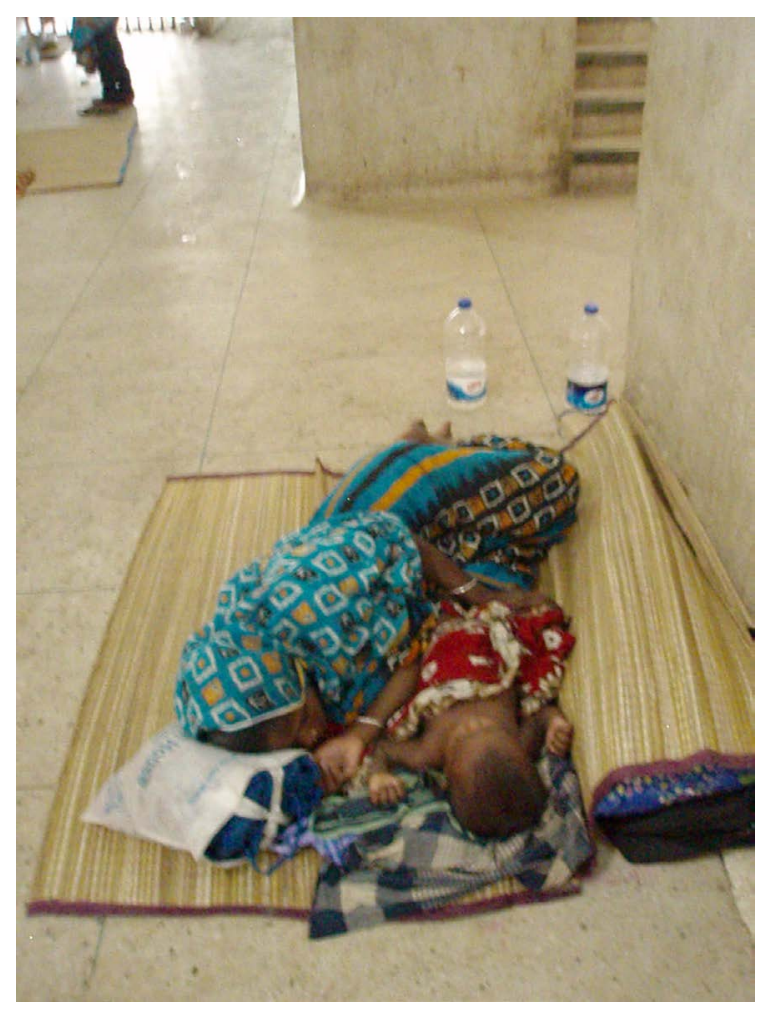

Figure 2. Dhaka medical college hospital. Lack of beds requires the patient and child to lie on the floor (photograph taken with permission of patient).

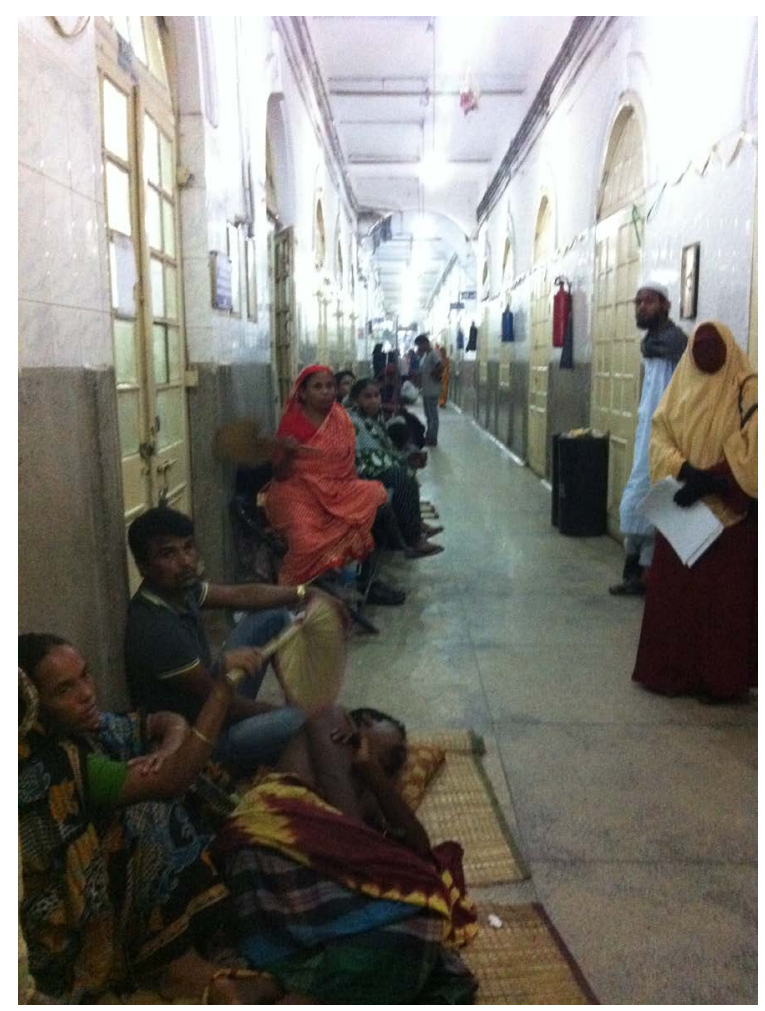

Figure 3. Inpatients at Dhaka medical college hospital placed in the hallway because of lack of available beds (photograph taken with permission of patients and families). 


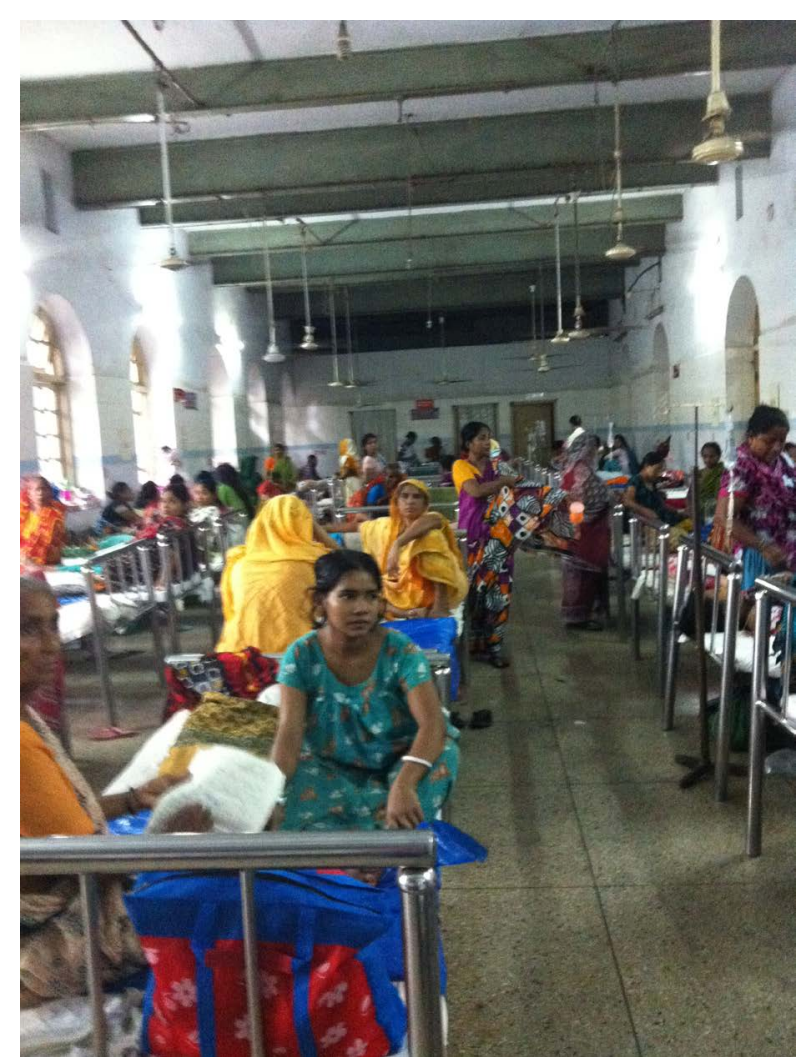

Figure 4. Dhaka medical college hospital. Open wards with no hand washing facilities (photograph taken with permission of patients and families).

and other furniture were soiled with secretions and excretions. Animals such as feral cats roamed the wards and mosquitoes were present. Not all hospitals had mosquito nets for patients. Nosocomial spread of dengue in hospital is a big risk to hospitalized patients in Bangladesh where dengue is endemic [29].

Other observations pertained to transmission of infectious agents by healthcare workers. Medical instruments such as stethoscopes were used without cleaning between patients. Hand washing was limited and doctors rarely used gloves were examining patients [28].

\section{Root Cause Analysis}

\subsection{Spread of Hospital Acquired Infection}

Hospital acquired infections can be caused by microorganisms already present in the patient's skin and mucosa (endogenous) or by microorganisms transmitted from another patient or from surrounding environment (exogenous). There are three common modes of transmission; direct contact, indirect contact through contaminated objects, and airborne droplets.

Direct physical contact between the source and the patient, such as person-to-person contact occurs between the patient and healthcare providers and/or family members [30].

Indirect contact can occur with contaminated inanimate objects like improperly sterilized instruments, dressing materials; contaminated fomites such as bed pans, blankets, and furniture [31]. The third mode of transmission is droplet infection which is the passage of the infectious agents through the air when the source and patient are in close proximity through sneezing and coughing [32].

In most cases, the hands of the health care workers are the source or the vehicle for transmission of microorganism from patient's skin into mucous (such as the respiratory tract) or normally sterile body compartments such blood, cerebrospinal fluid, and pleural fluid, and from other patients or the contaminated environment [30] [33]. One solution that nurses have used in LMICs is to have the patients' families perform hands-on-care for the patient and not touch the patients themselves in a setting with limited hand washing facilities [34]. 


\subsection{Development of Hospital Acquired Infection}

Incidence of HAIs is highest in large teaching or academic hospitals. An evaluation of high-risk patients has identified many medical interventions that can also increase nosocomial infections [35]. Any type of invasive procedure can expose a patient to the possibility of infection. Some common procedures that increase the risk of hospital-acquired infections include urinary bladder catheterization, respiratory procedures such as intubations or mechanical ventilation, gastric drainage tubes into the stomach through the nose or mouth, which can lead to aspiration pneumonia and infections of the sinus cavity, and invasive intravenous monitoring [36]. For instance in one hospital in Italy, a seven-month, multi-ward epidemic of multidrug-resistant Acinetobacter baumannii (MDRAB), an important cause of hospital acquired infection, was identified as starting predominantly in patients receiving invasive monitoring [37].

In a 2010 study of the microbiology of nosocomial infections in tertiary hospitals in Dhaka, Bangladesh, the majority of infections were Escherichia coli followed by Pseudomonas, Proteus species, Staphylococcus aureus, Klebsiella species, and Acinatobacter [38]. All infections were antibiotic resistant which is thought to be due to the widespread use of antibiotics. The leading risk factor was hospital stay greater than three days. Interestingly, different organisms were isolated from different objects. For instance, Escherichia coli was isolated from the operating table, the floor, and tap water, Pseudomonas was isolated from boiled water, and Proteus was isolated from operating room gloves [38].

\subsection{Consequences of Nosocomial Infections}

Nosocomial infections, or hospital-acquired infections (HAI), are among the most significant causes of morbidity and mortality in healthcare settings throughout the world [27] [37] [39]. The most common types of nosocomial infections are surgical wound infections, respiratory infections, genitourinary infections and gastrointestinal infections. The mortality attributed to nosocomial infection varies by country. Direct cause of death of one percent was reported from the United States [40]. In Thailand, there has been a rising incidence of hospital-acquired bacteremia (HAB) and healthcare-associated bacteremia (HCAB) [41]. Between 2004 and 2010, the incidence rate of HAB rose from 0.6 to 0.8 per 1000 patient-days and the cumulative incidence of HCAB increased from 1.2 to 2.0 per 100 readmissions. In a report from North Thailand, a total of 3424 patients out of 1,069,443 (0.3\%) at risk developed HAB and 2184 out of 119,286 (1.8\%) at risk had HCAB. Of these 1559 (45.5\%) and 913 (41.8\%) died within 30 days, respectively. Pneumonia, primary bacteremia, and meningitis are more likely to cause death [41].

Transmission of an infection with methicillin-resistant Staphylococcus aureus (MRSA) was associated with crowded bed occupancy [42]. Nosocomial infections furthermore increase the costs of healthcare due to added antimicrobial treatment and prolonged hospitalization. There is also the uncounted cost to society of the debility and death of its citizens from these infections.

Apart from causing morbidity, mortality and economic loss, nosocomial infections compromise medical and surgical treatment outcomes. These patients then become sources for spread of infections to other patients, medical personnel or family members before and after discharge [43].

\section{Recommendations}

\subsection{Organization of Hospital Acquired Infections Control Program in Bangladesh}

Hospital acquired infections constitutes an important health care problem in Bangladesh. An effective infection-control program must include the following as a minimum standard in an acute care hospital.

\subsubsection{Improvement of Structural Design}

- Bed-to-bed distance: In the Netherlands, a country with adequate medical resources, the bed-to-bed distance of $150 \mathrm{~cm}$ is recommended. In countries with limited medical resources such as Turkey, bed-to-bed distances are reported at $100 \mathrm{~cm}$. The infection rates are $7.2 \%$ and $13.4 \%$ respectively in the Netherlands and in Turkey [44]. In Bangladesh, the number of patients in need of admission to tertiary hospitals always exceeds the capacity for which it is designed and staffed. Creative solutions must be considered. For instance, crowding may be reduced by efficient discharge and shorter hospital stays. One option is to transfer the patients after improving from the acute crisis to their nearby district or upazilla hospitals in their communities. 
- Specific isolation rooms: Most of the hospitals in LMICs do not have specific isolation rooms. Severely infected patients and patient harboring dangerous organisms should be isolated and placed in separate rooms.

- Sinks and hand-rub dispensers: Every ward should have at least one sink. Hand-rub dispensers should be available at each bedside in each ward.

\subsubsection{Hand Hygiene Compliance}

Hand hygiene compliance was defined as hand washing with antiseptic soap and water-based or alcohol-based hand rubs for each of WHO's five moments for hand hygiene [45] [46]. Healthcare workers and family members should be educated with posters placed liberally around hospital corridors, in patient rooms, and in wards. Hand washing instructions are summarized in Table 1.

Hand hygiene compliance was achieved when the health workers performed this correctly. Multi-disciplinary focus groups were crucial to focusing infection-prevention programs on the target of interest and contributed to improved adherence to hand-hygiene protocols and reduced rates of HAIs [47] [48]. Hospitals should provide $70 \%$ ethyl alcohol and soap to healthcare workers for disinfecting their hands before and after touching patients and provide training and rewards for compliance. The benefit derived from hand hygiene protocol undoubtedly overweighs the cost of alcohol and soap [49].

\subsubsection{Aseptic Precaution during Major and Minor Procedures}

Table 2 summarizes the steps for aseptic technique [50]. All health care staff must maintain full aseptic precaution during any procedures that penetrate a body barrier. Procedures include the following: 1) All major and minor surgical procedures; 2) Surgical dressing; 3) Intravenous fluid administration; 4) Urethral catherization; 5) Intubation; and 6) Endoscopy.

\subsubsection{Knowledge and Practice of Hospital Waste Disposal and Management}

There is lack of attention on hospital waste management in both governmental and non-governmental sectors of Bangladesh. Due to the rapid increase of healthcare establishments in the country, the problem is also increasing [51] [52]. Knowledge about hospital waste and its management is very poor among health workers. A study conducted in one tertiary hospital of Bangladesh identified significant knowledge deficits among senior staff

\section{Table 1. Mandatory hand washing instructions.}

\section{MANDATORY HAND WASHING}

1. Before touching a patient

2. Before clean/aseptic procedure

3. After body fluid exposure risk

4. After touching a patient

5. After touching patient surroundings

Table 2. Steps for aseptic technique.

STEPS OF ASEPTIC TECHNIQUE

1. All procedures should be done in a designated isolated room

2. Personal protective equipment must be used including gloves, gowns, shoe covers, face shields, goggles and surgical masks

3. Use appropriate procedures for sterilization and disinfection of instruments and equipment

4. Clean and disinfect the dressing trolley

5. Wash and dry the hands; disinfect the hands and use sterile gloves

6. Clean and disinfect the area of procedure

7. Sterile draping of patient in the area of the procedure

8. In cases of major surgeries the appropriate antibiotics should be given within 1 hour of incision. Antibiotics should be discontinued within 24 hours of surgery

9. After the procedure, place the dirty instruments and the soiled material in proper container, clean and disinfect the trolley, wash and dry hands again 
nurses on hospital waste management [53]. Table 3 shows the results of knowledge testing.

In another cross-sectional study of seven hospitals in the Dhaka division of Bangladesh (1-tertiary, 3 secondary, and 3 primary level hospitals), 30\% of medical doctors and nurses and $60 \%$ of technologists and cleaning staff had inadequate knowledge of waste disposal. Five major problems were identified: lack of personal protective equipment, lack of equipment for final disposal of waste, lack of medical waste management-related staff, no proper policies or guidelines, and lack of a medical waste incinerator [54].

\subsection{Implementation of Waste Management in Hospitals of Bangladesh}

The Ministry of Health in Bangladesh addressed medical waste management as one of the priority programs and mandated the development of a national hospital waste management committee to handle the management of medical waste in all hospital level [55]. Table 4 and Table 5 summarize the guidelines for waste management [56].

\subsubsection{Rational Use of Antibiotics}

There is renewed focus on in appropriate use of antibiotics in developing countries, where the major burden of antibiotic resistance may exist [57]. The World Health Organization summarized the existing literature and the findings of antibiotic resistance [58]. WHO recommendations include the need to educate the public and to control and monitor pharmaceutical company promotional activities in the hospital environments. In an observa-

Table 3. Frequency distribution of knowledge about color-coded bin.

\begin{tabular}{cc} 
Characteristics & Frequency (percentage) \\
Knowledge about color-coded bin & Wrong answer (53.6\%) \\
Knowledge about black color bin & Wrong answer (32.0\%) \\
Knowledge about yellow color bin & Wrong answer (84.0\%) \\
Knowledge about red color bin & Wrong answer (40.0\%) \\
\hline
\end{tabular}

Table 4. Recommended color code in Bangladesh.

\begin{tabular}{cc}
\hline Type of waste & Color coded bins \\
General or non-hazardous & Black \\
Infectious, pathological, anatomical & Yellow \\
Sharp & Red \\
Radioactive & Silver \\
Recyclable waste & Green \\
Liquid & Blue \\
\hline
\end{tabular}

Table 5. Guidelines for waste management.

\begin{tabular}{|c|c|}
\hline ACTION & PROTOCOL \\
\hline Placement of color bins & $\begin{array}{l}\text { Appropriate container should be placed at all important location where particular wastes are generated. } \\
\text { Instruction on waste identification should be pasted over the containers. }\end{array}$ \\
\hline Waste collection & $\begin{array}{l}\text { Content of the container should not exceed three-quarters of its capacity. Collection of waste in colored } \\
\text { bag or colored covered bins with tie the neck tightly. During collection, containers should be replaced } \\
\text { with a new one. }\end{array}$ \\
\hline $\begin{array}{l}\text { In-hospital transportation } \\
\text { of waste }\end{array}$ & $\begin{array}{l}\text { Removal of waste must be executed within } 24 \text { hours. Waste should be transported by designated trolley } \\
\text { through the designated route. }\end{array}$ \\
\hline $\begin{array}{l}\text { Disposal of contaminated } \\
\text { waste procedure }\end{array}$ & $\begin{array}{l}\text { Specimens from patients with high-risk infections (such as hepatitis viruses or HIV) should be } \\
\text { conspicuously labeled with risk stickers. Specimens should be transported in approved containers. }\end{array}$ \\
\hline Personal hygiene & $\begin{array}{l}\text { At the end of official hours, health care workers and waste handlers should ensure about the cleanliness } \\
\text { of working place. They should wash hands and change the working dress before leaving for home. }\end{array}$ \\
\hline $\begin{array}{l}\text { Roles and responsibilities } \\
\text { of personnel }\end{array}$ & $\begin{array}{l}\text { Institutional head should develop a waste management committee and all the doctors should take part in } \\
\text { proper implementation of activities. Nurses should identify and segregate the waste according to } \\
\text { classification at the point of generation and also they should conduct health education session for the } \\
\text { patient and attendant on medical waste management. All the senior staff should be careful about } \\
\text { supervision and monitoring of the subordinate staff activities. }\end{array}$ \\
\hline
\end{tabular}


tional study of one hospital with a computerized prescribing guideline system that encouraged appropriate use of antimicrobials, analysis showed that hospital-acquired infections with resistant bacteria was reduced within seven-year period [59].

Widespread use of antibiotics also contributes to antibiotic resistance. A cross-sectional study from Saudi Arabia evaluated 327 pharmacies. Antibiotics were given without prescriptions $77.6 \%$ of the time [60]. Misuse of antibiotics in LMICs is common. Antibiotics are usually obtained from street pharmacies, used indiscriminately, and are a major cause of antibiotic resistance [61].

Clinical practice guidelines must be developed and enacted in LMICs. Guidelines will improve decision-making and therefore improve patient care. Such treatment guidelines need to be developed carefully and their implementation reviewed regularly.

\subsubsection{Education and Training of Health Care Workers}

A study examining training on the handling and the disposal of medical waste in a tertiary care hospital revealed that only 8.5\% respondents received training [62]. Training in waste management, aseptic technique, antibiotic use is essential and should be made compulsory for all healthcare facilities specially nursing staff to get their healthcare personnel trained from accredited training centers. These training sessions should be done on a continuous basis.

\subsubsection{Formulation and Implementation of National Guidelines on Basic Infection Control Measures} Resource-limited countries should develop national infection-control guidelines based on practical, evidencebased, low-cost, and simple preventive strategies [63]. Government hospitals and most of the private hospitals rarely have protocols in place. There is a great need for the development of guidelines and programs for basic infection control practices in all hospitals.

Guidelines should be evaluated after a certain period of implementation. Their effectiveness should be assessed by organizing audits as a standardized and systematic review of practice with timely feedback [64] [65].

\section{Conclusion}

Hospital acquired infections usually only receive public attention when there are epidemics. Although hidden from public attention, HAIs are a very real endemic and on-going problem. Maintaining a safe and hygienic work environment prevents the spread of HAIs. An effective infection control program in an acute-care hospital must include trained nursing staff, dedicated physicians in infection control, microbiological support, and data management support. We need improved healthcare structures, increased knowledge, effective guidelines, behavioral changes and attitude adjustment to reduce HAIs in Bangladesh.

\section{References}

[1] Khan, S.A. (2009) Nosochromial Infections: General Principles \& the Consequences, Importance of It's Control and an Outline of the Control Policy-A Review Article. Bangladesh Medical Journal, 38, 60-64. http://dx.doi.org/10.3329/bmj.v38i2.3576

[2] Mayon-White, R.T., Ducel, G., Kereseselidze, T., et al. (1988) An International Survey of the Prevalence of HospitalAcquired Infection. Journal of Hospital Infection, 11, 43-48. http://dx.doi.org/10.1016/0195-6701(88)90164-8

[3] Ponce-de-Léon, S. (1991) The Needs of Developing Countries and the Resources Required. Journal of Hospital Infection, 18, 376-381. http://dx.doi.org/10.1016/0195-6701(91)90044-9

[4] Western, K.A., St John, R. and Shearer, L.A. (1982) Hospital Infection Control and International Perspectives. Infection Control, 3, 453-445.

[5] Macias, A.E., Muñoz, J.M., Bruckner, D.A., et al. (1999) Parenteral Infusion Contamination in a Multi-Institutional Survey in Mexico: Considerations for Nosocomial Mortality. American Journal of Infection Control, 27, 285-290. http://dx.doi.org/10.1053/ic.1999.v27.a92879

[6] Rezende, E.M., Couto, B.R., Starling, C.E., et al. (1998) Prevalence of Nosocomial Infections in General Hospitals in Belo Horizonte. Infection Control and Hospital Epidemiology, 19, 872-876. http://dx.doi.org/10.2307/30141571

[7] Grimes, D.A., Peterson, H.B. and Rosenberg, M.J. (1982) Sterilization-Attributable Deaths in Bangladesh. International Journal of Gynecology \& Obstetrics, 20, 149-154. http://dx.doi.org/10.1016/0020-7292(82)90029-7

[8] World Health Organization (WHO) (2009) Guidelines on Hand Hygiene in Health Care. 
http://www.who.int/gpsc/5may/tools/9789241597906/en/

[9] Bauer, T.M., Ofner, E., Just, H.M., et al. (1990) An Epidemiological Study Assessing the Relative Importance of Air Borne and Direct Contact Transmission of Microorganisms in a Medical Intensive Care Unit. Journal of Hospital Infection, 15, 301-309. http://dx.doi.org/10.1016/0195-6701(90)90087-5

[10] Semmelweis, I. (1983) Etiology, Concept, and Prophylaxis of Childbed Fever. Carter, K.C., Ed. The University of Wisconsin Press, Madison.

[11] World Health Organization (WHO) (2006) Global Patient Safety Challenge: Clean Care Is Safer Care. http://www.who.int/gpsc/resources/newsalert/sept2006/en/

[12] Zerin, S.A. and Ahmed, M.B. (2009) Hospital Waste Management in Dhaka: A Threat. Bangladesh Research Publications Journal, 3, 796-811.

[13] Usluer, G., Ozgunes, I., Leblebicioglu, H. and The Turkish Antibiotic Utilization Study Group (2005) A Multicenter Point-Prevalence Study: Antimicrobial Prescription Frequencies in Hospitalized Patients in Turkey. Annals of Clinical Microbiology and Antimicrobials, 4, 16. http://dx.doi.org/10.1186/1476-0711-4-16

[14] Raka, L. (2009) Lowbury Lecture 2008: Infection Control and Limited Resources Searching for the Best Solutions. Journal of Hospital Infection, 72, 292-298. http://dx.doi.org/10.1016/j.jhin.2009.03.017

[15] Parna, F.H., Latif, T., Sultana, N., et al. (2013) Maternal \& Fetal Outcome of Eclamptic Patients Admitted in Obstetrics \& Gynaecology Department of Secondary Care Hospital in Bangladesh. Mymensingh Medical Journal, 22, 522526.

[16] Hossain, M., Ullah, A.T., Regmi, S., et al. (2011) Safety and Efficacy of the Supracostal Access for Percutaneous Nephrolithotomy: Our Initial Experience. Bangladesh Medical Research Council Bulletin, 3, 34-38. http://dx.doi.org/10.3329/bmrcb.v37i1.7797

[17] Atiq, M.T., Joarder, A.H., Alam, M.M., et al. (2011) Analysis of Postoperative Complications Following Total Thyroidectomy. Mymensingh Medical Journal, 20, 238-244.

[18] Del Rossi, C., Fontechiari, S., Casolari, E., et al. (2008) Treatment of Congenital Anomalies in a Missionary Hospital in Bangladesh: Results of 17 Paediatric Surgical Missions. Acta Bio-Medica, 79, 260-263.

[19] Jahan, S., Das, T., Mahmud, N., et al. (2011) A Comparative Study between Laparoscopically Assisted Vaginal Hysterectomy and Vaginal Hysterectomy: Experience in a Tertiary Diabetes Care Hospital in Bangladesh. Journal of Gynecological Endoscopy and Surgery, 2, 79-84. http://dx.doi.org/10.4103/0974-1216.114078

[20] Zaman, M.A. and Ahmed, M.K. (1993) Antibiotic in General Surgery: Selection, Timing and Duration of Administration. Bangladesh Medical Research Council Bulletin, 19, 1-7.

[21] Hussain, M.A., Fazal, M.A., Ahmed, A., et al. (1991) Nosocomial Infection-A Cross-Sectional Study in Surgical Wards of Dhaka Medical College Hospital. Journal of Preventive and Social Medicine: JOPSOM, 10, 70-73.

[22] Faruquzzaman, M.M. (2011) Positive Associations of Nosocomial Infections in Surgical Ward with Etiological Clinical Factors. Bratislavské Lekárske Listy, 112, 273-277. http://bmj.fmed.uniba.sk/2011/11205-09.pdf

[23] Islam, M.S., Luby, S.P., Sultana, R., et al. (2014) Family Caregivers in Public Tertiary Care Hospitals in Bangladesh: Risks and Opportunities for Infection Control. American Journal of Infection Control, 42, 305-310. http://dx.doi.org/10.1016/j.ajic.2013.09.012

[24] Zaman, S. (2004) Poverty and Violence, Frustration and Inventiveness: Hospital Ward Life in Bangladesh. Social Science \& Medicine, 59, 2025-2036. http://dx.doi.org/10.1016/j.socscimed.2004.03.007

[25] Bhuiyan, M.U., Luby, S.P., Zaman, R.U., et al. (2014) Incidence of and Risk Factors for Hospital-Acquired Diarrhea in Three Tertiary Care Public Hospitals in Bangladesh. The American Journal of Tropical Medicine and Hygiene, 91, 165-172. http://dx.doi.org/10.4269/ajtmh.13-0484

[26] Gurley, E.S., Zaman, R.U., Sultana, R., et al. (2010) Rates of Hospital-Acquired Respiratory Illness in Bangladeshi Tertiary Care Hospitals: Results from a Low-Cost Pilot Surveillance Strategy. Clinical Infectious Diseases, 50, 10841090. http://dx.doi.org/10.1086/651265

[27] Allegranzi, B., Nejad, S.B., Combescure, C., et al. (2011) Burden of Endemic Health-Care-Associated Infection in Developing Countries: Systematic Review and Meta-Analysis. The Lancet, 377, 228-241. http://dx.doi.org/10.1016/S0140-6736(10)61458-4

[28] Rimi, N.A., Sultana, R., Luby, S.P., et al. (2014) Infrastructure and Contamination of the Physical Environment in Three Bangladeshi Hospitals: Putting Infection Control into Context. PLoS ONE, 9, e89085. http://dx.doi.org/10.1371/journal.pone.0089085

[29] Faruque, L.I., Zaman, R.U., Alamgir, A.S., et al. (2012) Hospital-Based Prevalence of Malaria and Dengue in Febrile Patients in Bangladesh. The American Journal of Tropical Medicine and Hygiene, 86, 58-64. http://dx.doi.org/10.4269/ajtmh.2012.11-0190 
[30] Sanderson, P.J. and Weissler, S. (1992) Recovery of Coliforms from the Hands of Nurses and Patients: Activities Leading to Contamination. Journal of Hospital Infection, 21, 85-93. http://dx.doi.org/10.1016/0195-6701(92)90027-J

[31] Schulster, L. and Chinn, R.L. (2003) Guidelines for Environmental Infection Control in Health-Care Facilities. Recommendations of CDC and the Healthcare Infection Control Practices Advisory Committee (HICPAC). MMWR Recommendations and Reports, 52, 1-42.

[32] Voirin, N., Barret, B., Metzger, M.H., et al. (2009) Hospital-Acquired Influenza: A Synthesis Using the Outbreak Reports and Intervention Studies of Nosocomial Infection (ORION) Statement. Journal of Hospital Infection, 71, 1-14. http://dx.doi.org/10.1016/j.jhin.2008.08.013

[33] Pittet, D., Allegranzi, B., Storr, J., et al. (2008) Infection Control as a Major World Health Organization Priority for Developing Countries. Journal of Hospital Infection, 68, 285-292. http://dx.doi.org/10.1016/j.jhin.2007.12.013

[34] Hadley, M.B., Blum, L.S., Mujaddid, S., et al. (2007) Why Bangladesh Nurses Avoid "Nursing”: Social and Structural Factors on Hospital Wards in Bangladesh. Social Science \& Medicine, 64, 1166-1177. http://dx.doi.org/10.1016/j.socscimed.2006.06.030

[35] Hassan, K.A., Hasan, M.K., Chowdhury, M.G., et al. (2010) Aspects of Infection in Intensive Care Unit-Prevention and Control. Mymensingh Medical Journal, 19, 474-476.

[36] Leroy, O., d’Escrivan, T., Devos, P., et al. (2005) Hospital-Acquired Pneumonia in Critically Ill Patients: Factors Associated with Episodes Due to Imipenem-Resistant Organisms. Infection, 33, 129-135. http://dx.doi.org/10.1007/s15010-005-4021-8

[37] Cristina, M.L., Spagnolo, A.M., Ottria, G., et al. (2011) Spread of Multidrug Carbapenem-Resistant Acinetobacter baumannii in Different Wards of an Italian Hospital. American Journal of Infection Control, 39, 790-794. http://dx.doi.org/10.1016/j.ajic.2011.01.016

[38] Mohiuddin, M., Haq, J.A., Hoq, M.M., et al. (2010) Microbiology of Nosocomial Infection in Tertiary Hospitals of Dhaka City and Its Impact. Bangladesh Journal of Medical Microbiology, 4, 32-38.

[39] Klevens, R.M., Edwards, J.R., Richards, C.L., et al. (2007) Estimating Health Care-Associated Infections and Deaths in US Hospitals, 2002. Public Health Reports, 122, 160-166.

[40] ECDC (2008) Annual Epidemiological Report on Communicable Diseases in Europe, 2008: Report on the State of Communicable Diseases in the EU and EEA/EFTA Countries. http://ecdc.europa.eu/en/publications/Publications/0812_SUR_Annual_Epidemiological_Report_2008.pdf

[41] Hongsuwan, M., Srisamang, P., Kanoksil, M., et al. (2014) Increasing Incidence of Hospital-Acquired and HealthcareAssociated Bacteremia in Northeast Thailand: A Multicenter Surveillance Study. PLoS ONE, 9, e109324. http://dx.doi.org/10.1371/journal.pone.0109324

[42] Borg, M.A., Suda, D. and Scicluna, E. (2008) Time-Series Analysis of the Impact of Bed Occupancy Rates on the Incidence of Methicillin-Resistant Staphylococcus aureus Infection in Overcrowded General Wards. Infection Control \& Hospital Epidemiology, 29, 496-502. http://dx.doi.org/10.1086/588157

[43] Cunningham, J.B., Kernohan, W.G. and Rush, T. (2006) Bed Occupancy, Turnover Intervals and MRSA Rates in English Hospitals. British Journal of Nursing, 15, 656-660. http://dx.doi.org/10.12968/bjon.2006.15.12.21398

[44] Alp, E., Leblebicioglu, H., Doganay, M., et al. (2011) Infection Control Practice in Countries with Limited Resources. Annals of Clinical Microbiology and Antimicrobials, 10, 36. http://dx.doi.org/10.1186/1476-0711-10-36

[45] Sax, H., Allegranzi, B., Uçkay, I., et al. (2007) My Five Moments for Hand Hygiene: A User-Centered Design Approach to Understand, Train, Monitor and Report Hand Hygiene. Journal of Hospital Infection, 67, 9-21. http://dx.doi.org/10.1016/j.jhin.2007.06.004

[46] Marra, A.R., Guastelli, L.R., de Araujo, C.M., et al. (2010) Positive Deviance: A New Strategy for Improving Hand Hygiene Compliance. Infection Control \& Hospital Epidemiology, 31, 12-20. http://dx.doi.org/10.1086/649224

[47] Joshi, S.C., Diwan, V., Tamhankar, A.J., et al. (2012) Qualitative Study on Perceptions of Hand Hygiene among Hospital Staff in a Rural Teaching Hospital in India. Journal of Hospital Infection, 80, 340-344. http://dx.doi.org/10.1016/j.jhin.2011.12.017

[48] Thomas, M., Gillespie, W., Krauss, J., et al. (2005) Focus Group Data as a Tool in Assessing Effectiveness of a Hand Hygiene Campaign. American Journal of Infection Control, 33, 368-373. http://dx.doi.org/10.1016/j.ajic.2005.03.011

[49] Hasan, Z. (2010) How Big a Challenge to Initiate Three Basic Infection Control Practices in Hospitals of Bangladesh? Bangladesh Society of Medical Microbiologists. Bangladesh Journal of Medical Microbiology, 4, 1-2.

[50] National Institute for Health and Clinical Excellence, NICE (2008) Surgical Site Infection. Prevention and Treatment of Surgical Site Infection. NICE Publication, UK. https://www.nice.org.uk/guidance/cg74

[51] Pruss, A., Giroult, E. and Rushbrook, P. (1999) Safe Management of Wastes from Health-Care Activities. World Health Organization, Geneva. http://apps.who.int/iris/bitstream/10665/42175/1/9241545259.pdf 
[52] Qadir, S., Akhtar, M.N., Hassan, M.U., et al. (2014) A Study of Hospital Waste Disposal Practice in a Tertiary Care Hospital. Gomal Journal of Medical Sciences, 12, 64-67.

http://www.gjms.com.pk/ojs/index.php/gjms/article/view/1039/647

[53] Uddin, M.N., Islam, M.R. and Yesmin, K. (2014) Knowledge on Hospital Waste Management among Senior Staff Nurses Working in a Selected Medical College Hospital of Bangladesh. Journal of Waste Management, 2014, Article ID: 573069. http://www.hindawi.com/journals/jwm/2014/573069/

[54] Sarker, M.A.B., Harun-Or-Rashid, M., Hirosawa, T., et al. (2014) Evaluation of Knowledge, Practices, and Possible Barriers among Healthcare Providers regarding Medical Waste Management in Dhaka, Bangladesh. Medical Science Monitor: International Medical Journal of Experimental and Clinical Research, 20, 2590-2597. http://dx.doi.org/10.12659/MSM.890904

[55] Ministry of Health and Family Welfare, MOHFW (2011) “Medical Waste Management” in Environmental Assessment and Action Plan for the Health, Population and Nutrition Sector Development Program (HPNSDP). 8-10. http://www.mohfw.gov.bd/index.php?option=com_content\&view=article\&id=166\&Itemid=150\&lang=en

[56] Directorate General of Health Services (2014) Medical Waste Management-Hospital Services Management. DGHS, Mohakhali, 1-119. www.hsmdghs-bd.org/Documents/MWM/Doc_Training\%20Manual.pdf

[57] Reed, D. and Kemmerly, S.A. (2009) Infection Control and Prevention: A Review of Hospital-Acquired Infections and the Economic Implications. The Ochsner Journal, 9, 27-31.

[58] World Health Organization, WHO (2001) Global Strategy for Containment of Antimicrobial Resistance. 1-105. http://www.who.int/drugresistance/WHO_Global_Strategy_English.pdf

[59] Pestotnik, S.L., Classen, D.C., Evans, R.S., et al. (1996) Implementing Antibiotic Practice Guidelines through Computer-Assisted Decision Support: Clinical and Financial Outcomes. Annals of Internal Medicine, 124, 884-890. http://dx.doi.org/10.7326/0003-4819-124-10-199605150-00004

[60] Bin Abdulhak, A.A., Altannir, M.A., Almansor, M.A., et al. (2011) Non Prescribed Sale of Antibiotics in Riyadh, Saudi Arabia: A Cross Sectional Study. BMC Public Health, 11, 538. http://dx.doi.org/10.1186/1471-2458-11-538

[61] Okeke, I.N., Lamikanra, A. and Edelman, R. (1999) Socioeconomic and Behavioral Factors Leading to Acquired Bacterial Resistance to Antibiotics in Developing Countries. Emerging Infectious Diseases, 5, 18-27. http://dx.doi.org/10.3201/eid0501.990103

[62] Akter, N., Chowdhury, A.M.R. and Kazi, N.M. (1999) Hospital Waste Disposal in Bangladesh with Special Reference to Dhaka City and Its Environmental. Evaluation, Special Publication 1999, No. 87, ICDDRB. http://citeseerx.ist.psu.edu/viewdoc/download?doi=10.1.1.530.8191\&rep=rep1\&type=pdf

[63] Apisarnthanarak, A. and Fraser, V.J. (2009) Feasibility and Efficacy of Infection-Control Interventions to Reduce the Number of Nosocomial Infections and Drug-Resistant Microorganisms in Developing Countries: What Else Do We Need? Clinical Infectious Diseases, 48, 22-24.

[64] Moongtui, W., Gauthier, D.K. and Turner, J.G. (2000) Using Peer Feedback to Improve Hand Washing and Glove Usage among Thai Health Care Workers. American Journal of Infection Control, 28, 365-369. http://dx.doi.org/10.1067/mic.2000.107885

[65] Miyachi, H., Furuya, H., Umezawa, K., et al. (2007) Controlling Methicillin-Resistant Staphylococcus aureus by Stepwise Implementation of Preventive Strategies in a University Hospital: Impact of a Link-Nurse System on the Basis of Multidisciplinary Approaches. American Journal of Infection Control, 35, 115-121. http://dx.doi.org/10.1016/j.ajic.2006.09.003. 